\title{
How Do Companies Respond to Environmental, Social and Governance (ESG) ratings? Evidence from Italy
}

\author{
Ester Clementino $^{1,3} \cdot$ Richard Perkins $^{2}$
}

Received: 9 July 2019 / Accepted: 14 January 2020 / Published online: 31 January 2020

(c) The Author(s) 2020

\begin{abstract}
While a growing number of firms are being evaluated on environment, social and governance (ESG) criteria by sustainability rating agencies (SRAs), comparatively little is known about companies' responses. Drawing on semi-structured interviews with companies operating in Italy, the present paper seeks to narrow this gap in current understanding by examining how firms react to ESG ratings, and the factors influencing their response. Unique to the literature, we show that firms may react very differently to being rated, with our analysis yielding a fourfold typology of corporate responses. The typology captures conformity and resistance to ratings across two dimensions of firm behaviour. We furthermore show that corporate responses depend on managers' beliefs regarding the material benefits of adjusting to and scoring well on ESG ratings and their alignment with corporate strategy. In doing so, we challenge the idea that organisational ratings homogenise organisations and draw attention to the agency underlying corporate responses. Our findings also contribute to debates about the impact of ESG ratings, calling into question claims about their positive influence on companies' sustainability performance. We conclude by discussing the wider empirical, theoretical and ethical implications of our paper.
\end{abstract}

Keywords ESG $\cdot$ Rating $\cdot$ Sustainability $\cdot$ Investors $\cdot$ Corporate response

\section{Introduction}

An increasing number of companies are being evaluated by entities known as sustainability rating agencies (referred to hereafter as SRAs or rating agencies) (Busch et al. 2016; Drempetic et al. 2019). The ratings they produce are primarily intended to provide stakeholders with data on various environment, social and governance (ESG) indicators. These indicators are increasingly framed by SRAs as capturing

The research was undertaken whilst the author was at the London School of Economics and Political Science.

Richard Perkins

r.m.perkins@1se.ac.uk

1 Department of Geography and Environment, London School of Economics and Political Science, Houghton Street, London WC2A 2AE, UK

2 Department of Geography and Environment and Grantham Research Institute on Climate Change and the Environment, London School of Economics and Political Science, Houghton Street, London WC2A 2AE, UK

3 Present Address: United Nations System Staff College (UNSSC), Viale Maestri del Lavoro 10, 10127 Torino, Italy firms' exposure to, and management of, various non-financial risks and opportunities. The growing role of ESG ratings is constitutive of a broader trend towards an "audit society" (Power 1997) wherein "the principles and techniques of accountancy and financial management are applied to the governance of people and organisations' (Shore and Wright 2015, p. 24). It can also be conceptualised as symptomatic of a shift toward neoliberal modes of governance emphasising transparency, accountability and market discipline (Christophers 2017).

Past research concerned with ESG ratings has largely been preoccupied with examining the statistical relationship between corporate social responsibility (CSR)-related performance (as measured by one or more ESG metric) and financial performance (e.g. Aouadi and Marsat 2018; Duque-Grisales and Aguilera-Caracuel 2019). The present paper examines a different set of issues which have received far less attention, namely: (a) how firms respond to being rated; (b) the reasons for their response; and (c) whether ESG ratings contribute to substantive improvements in firms' sustainability performance. That comparatively limited work has been undertaken into corporate responses is perhaps surprising. ESG ratings provide one of the few 
comparable sources of data on a wide range of CSR-related policies, practices and performances (Crane et al. 2019). As such, ratings might be expected to assume considerable strategic significance to firms, most notably by influencing how key audiences perceive, value and engage with them (Martins 2005). Foremost amongst these are investors who, it is suggested, increasingly use ESG data to govern the ethical and sustainability behaviour of firms in which they invest (Amel-Zadeh and Serafeim 2018; van Duuren et al. 2016). Analysing firms' responses provides an opportunity to better understand whether and, if so, how, external evaluations shape corporate decision-making and action in the area of $\mathrm{E}$, $\mathrm{S}$ and $\mathrm{G}$ (Chrun et al. 2016). This is important for scrutinising claims about the substantive contribution of informationbased governance to CSR, and whether such approaches give rise to substantive or symbolic change (Depoers et al. 2016; Kim and Lyon 2011). A better understanding of corporate responses is also important because it sheds light on the sustainability implications of the growing amounts of capital which, to a greater or lesser degree, is being invested taking account of ESG-related factors (Amel-Zadeh and Serafeim 2018; Drempetic et al. 2019).

Based on in-depth interviews with sustainability managers in Italian companies, we make several important contributions. The first is to provide novel insights into how firms respond to being rated. Previous work on ESG ratings has tended to narrowly frame the range of possible responses, for example, in terms of the degree to which firms "improve" their environmental or social performance following evaluation (Chatterji and Toffel 2010; Slager and Chapple 2016). Answering calls for more disaggregated analyses in studies of organisational ratings (Szper 2013), our inquiry reveals a more diverse set of responses to ratings. Categorising these responses yields a fourfold typology, which we label as 'passive conformity', 'active conformity', 'passive resistance' and 'active resistance'. In identifying this heterogeneity, we challenge the idea that firms are unconditionally governed by ratings (Chelli and Gendron 2013), and expose the agency underlying corporate responses to external evaluation.

A second contribution is to shed light on the reasons why firms may react differently to being rated. Past studies have had comparatively little to say about this issue, beyond locating a handful of measurable determinants (e.g. current score) which lead certain firms to improve their environmental and/ or social performance more than others. Our analysis reveals that whether firms conform to, or resist, the requirements of ESG ratings largely depends on commercial rather than wider ethical considerations. More specifically, corporate responses depend on managers' perceptions regarding the business value of positively responding to ESG ratings, and their alignment with wider corporate objectives and strategy. In making these observations, our study helps connect work on ESG ratings with a longer-standing body of literature concerned with strategic, materiality-based drivers of CSR (Clemens and Douglas 2005; Malik 2015; Pedersen and Gwozdz 2014). Based on self-reported evaluations, a third contribution is to offer insights into whether ESG ratings impact firms' substantive sustainability performance ${ }^{1}$ (Perez-Batres et al. 2012). Our findings sound a note of caution toward claims about the positive influence of ESG ratings (Oekom 2017; Shvarts et al. 2018): although contributing to enhanced CSR-related organisational capabilities, few of our respondents believed that SRAs' evaluations made a significant difference to firms' substantive sustainability performance. Indeed, to the extent that some firms in the sample "gamed" ESG ratings, there is a danger that external evaluations may encourage firms to engage in ethically irresponsible actions.

The rest of the paper proceeds as follows. The "Literature Review" section introduces ESG ratings and provides an overview of prior studies. Next, drawing on salient literatures, we theorise corporate responses and their determinants. "Research Design and Methods" describes our methodology, sample and data collection. Findings are presented in the "Results and Analysis" section, followed by a discussion of the main contributions of the work. The final section offers concluding remarks, and reflects on the wider implications of the paper for theory, practice and business ethics.

\section{Literature Review}

\section{A Primer on ESG Ratings}

ESG ratings are 'evaluations of a company based on a comparative assessment of their quality, standard or performance on environmental, social or governance issues' (SustainAbility 2018, p. 4). SRAs evaluate firms, and supply data, on specific attributes within E, S and G categoriessuch as pollutant emissions, human rights and management (Avetisyan and Hockerts 2017). They also invariably provide an overall rating of firms' performance based on a composite score of individual ESG issues. Many agencies additionally produce ESG- and/or sustainability-themed indices, comprising lists of companies-selected from a wider universe of rated companies-which meet certain ESG thresholds. Some noteworthy examples are the Dow Jones Sustainability Index (DJSI), the FTSE4Good Index, and the MSCI ESG Indices (Searcy and Elkhawas 2012).

\footnotetext{
${ }^{1}$ By substantive, we refer to firms' environmental performance (e.g. reduced emissions or resource consumption) or organisational capabilities which are required to fulfil meaningful commitments to sustainability (Hyatt and Berente 2017).
} 
Rating agencies typically make their evaluations based on publicly available information (e.g. from mandatory non-financial disclosures), third-party research, firms' sustainability/integrated reports and information on corporate websites (Jackson et al. 2019). Some agencies, such as RobecoSAM, send questionnaires to firms, while others provide companies the opportunity to review and comment on profiles before finalising them. SRAs employ a range of 70 to 1000 indicators on different issues (Abramskiehn et al. 2015).

The past decade has witnessed growing investor demand for ESG data in response to, amongst other factors, increased awareness of the financial materiality of ESG factors and increased client demand such as that from asset owners (van Duuren et al. 2016). Investors use ESG ratings in several ways, including assessing and managing their exposure to ESG-related risks, and engaging with investee companies. Likewise, sustainability indices are commonly employed to assess the performance of responsible firms against a wider set of comparable peers, as well as to construct responsible investment products (Slager et al. 2012).

ESG ratings have received a mixed reception. For their proponents, ratings address information asymmetries by providing comprehensive, systematised and comparable data for a significant number of publicly listed firms. In doing so, they play an important role in helping stakeholders apprehend, evaluate and manage the increasingly complex, multi-faceted nature of business ethics and sustainability (Cappucci 2018). Yet ratings have also attracted considerable criticism. One set of critiques have focused on the underlying data quality (Doyle 2018; Drempetic et al. 2019). Others have questioned the validity of ESG ratings, with studies documenting non-trivial differences in the way that different SRAs conceptualise E, S and G, and the weights used to compile scores (Chatterji et al. 2016; Semenova and Hassel 2015). More fundamental critiques have centred on how ratings seek to define, naturalise or impose a common framework for the measurement of social and environmental responsibility (Chelli and Gendron 2013). Far from being neutral, such rating frameworks can be interpreted as social and commercial constructions, with different SRAs purposely seeking to differentiate their ratings offer from those of competitors (Eccles and Stroehle 2018). Such observations raise ethical questions about how firms' ESG performance is being defined, measured and framed by what are predominantly profit-oriented intermediaries.

\section{Previous Work on Corporate Responses to ESG Ratings}

Only a relatively small number of studies have examined how firms respond to ESG ratings. Chelli and Gendron (2013) highlight how ratings 'promote a regime of exclusion and inclusion' (p. 200), creating reward systems for high performance firms (e.g. by including them in a select index), whilst sanctioning firms scoring less well (e.g. by excluding them). Supporting these ideas, Slager and Chapple's (2016) statistical analysis finds that firms facing exclusion from the FTSE4Good Index following the introduction of new criteria were more likely to improve their performance in the following year, as were firms which actively advertised the fact that they were part of the Index. Chatterji and Toffel (2010) take a wider perspective, providing large sample evidence that US firms which received low scores on environmental ratings improved their performance (as measured by corporatewide toxic pollution) more than their peers never rated or that received a more positive evaluation. Adopting a similar approach, Sharkey and Bromley (2014) investigate the indirect effects of ESG ratings, showing that rated firms (but not unrated ones) reduced their pollution more as a greater share of their counterparts were rated. The idea that firms are responsive to ESG ratings also finds some support in qualitative work. Using survey evidence, Searcy and Elkhawas (2012) report several steps taken by Canadian firms seeking to be included in, and remain within, the DJSI. Likewise, Shvarts et al. (2018) show that oil and gas firms operating in Russia disclosed more environment-related information after the introduction of a third-party environmental rating, with some adjustments in the format in which they reported data.

Three further contributions offer a more critical perspective on ESG ratings. Using formal mathematical modelling, Adam and Shavit (2008) show that, through their limited membership lists, sustainability indices create inadequate incentives for most excluded firms to invest in CSR. In line with this result, Scalet and Kelly's (2009) empirical study finds that most firms did little to publicly acknowledge or address the negative factors which contributed to them being dropped from major CSR rankings. Gauthier and Wooldridge (2018) invoke the idea of compensatory tactics. Aware that many SRAs allow high scores in certain dimensions of CSR to compensate for poor ones in others, the authors suggest that firms may respond to low CSR ratings by investing in less costly and disruptive non-core business practices (as opposed to core ones).

In the next section, we develop our own theoretical ideas, exploring the case that firms may variously conform to, as well as resist, ESG ratings.

\section{Theorising Corporate Responses}

\section{Conformity to Ratings}

Our starting point for thinking about firm responses to ESG ratings comes from a literature which has explored the impact of ratings and rankings in other (i.e. non-ESG) domains of organisational life (e.g. Martins 2005; Pollock 
et al. 2018; Szper 2013). A key suggestion of this work is that evaluation systems interact with, and moreover shape, the very objects they seek to evaluate. In a widely cited contribution, Espeland and Sauder (2007) invoke the idea of reactivity to capture these dynamics, arguing that organisations adapt to principles, values and criteria embedded in ratings and ranking measures. The authors identify two key mechanisms underlying reactivity. The first is through so-called "self-fulfilling prophesies", described as "processes by which reactions to social measures confirm the expectations or predictions that are embedded in measures or which increase the validity of the measure by encouraging behaviour that conforms to it' (p. 11). Another mechanism is "commensuration" whereby organisations are compared against one another using a common metric, itself dependent on efforts to 'reduce and simplify disparate information into numbers' (Espeland and Stevens 1998, p. 316). Commensuration affects cognition, rendering certain dimensions of quality salient, authoritative and real, whilst deflecting attention from others.

An important insight from Espeland and Sauder's work is that, while rated entities may exhibit considerable scepticism toward rankings, they nevertheless often respond to them. Such reactivity stems from the belief that the decision-making of external stakeholders is influenced by organisational evaluations (see also Martins 2005). This motivates reflexive, anticipatory action, both from the promise of positive prospects which might come from a higher score/ranking, but also the fear of the negative implications of a falling or unfavourable one. To this end, rated entities may pay increased attention to the data and methodology underpinning ratings, and allocate greater resources to areas which are known to boost scores.

The idea of organisational alignment with externally defined conceptions of ideal or desirable behaviour is also taken up by the literature on new institutionalism. A core expectation of this work is that organisations become more isomorphic (i.e. similar) over time as they conform to institutionalised rules, norms and practices (DiMaggio and Powell 1983). Viewed through the lens of new institutionalism, a firm might adjust its CSR-related behaviours in line with the criteria enshrined in major ESG ratings because of their perceived, taken-for-granted status as "best" or "appropriate" practice (Déjean et al. 2004; Elbasha and Avetisyan 2018). Conformity might also result from the coercive requirements of powerful organisations which can sanction non-compliance through their control of important resources. One such stakeholder group in the present context are investors (AmelZadeh and Serafeim 2018). A further possibility is that firms may seek to emulate the ESG policies, practices and scores of what are perceived as influential or successful peers-a form of mimetic isomorphism potentially underpinned by benchmarking activities (Locke 2014; Searcy and Buslovich 2014; Sharkey and Bromley 2014).

Structuralist variants of institutional theory suggest that organisations passively, and even unconsciously, conform to institutionalised requirements, beliefs and templates (Boxenbaum and Jonsson 2008). Yet agent-centred, strategic approaches point to more active and furthermore proactive responses to institutional pressures (Rao 2004). Hence, rather than simply adhering to a socially constructed environment, it is suggested that actors may purposefully exploit institutional demands in order to advance their own organisational goals (Suchman 1995). Strategic conformity of this kind is identified in a growing body of work in CSR concerned with 'more proactive, value-creating responses to institutional pressures' (Pedersen and Gwozdz 2014, p. 249). According to this literature, certain firms may seek to leverage the benefits of positively engaging with CSR, seeking out opportunities by going beyond institutionalised expectations (Damert and Baumgartner 2018). Active efforts to secure an improved external reputation and organisationlevel differentiation advantage by scoring well on ESG ratings and becoming a sustainability "leader" could be situated within this frame.

In summary, work on reactivity and isomorphism suggests that firms are likely to conform to ESG ratings, internalising, adapting to and seeking to improve their scores on constituent criteria. As such, the very act of evaluation might be expected to transform rated entities, with corporations becoming more like the template of "good" ESG practice institutionalised by SRAs. A further implication is that firms' sustainability performance may improve, notably on those dimensions measured, weighted and valorised by popular ratings.

\section{Resistance to Ratings}

While centrally emphasising conformity, the wider literature on rankings and ratings nevertheless acknowledges the possibility that organisations may resist external evaluations (Martins 2005). Past empirical work-albeit mainly in the area of educational rankings - has therefore documented a range of potential responses which go beyond internalising ratings criteria, and adjusting organisational policy, practice and performance accordingly. One is to emphasise attributes neglected by rankings or to highlight their superior position when placed in alternative comparison groups (Elsbach and Kramer 1996; Moos 2015). Another response is to dismiss ratings, or else criticise their constituent criteria, weights or data (Espeland and Sauder 2007; Locke 2014). A further reaction is to engage with raters, both to better understand their methodology, but also to shape their criteria, weights or data sources (Pollock et al. 2018). 
The suggestion that organisations might respond to external institutional pressures in ways other than conformity is also developed theoretically by Oliver (1991) who challenges the deterministic predictions of new institutionalism. Beyond acquiescence (i.e. complying with, and adjusting to, institutionalised requirements), the author proposes four different categories of strategic response, capturing increasingly active forms of organisational resistance: (1) compromise (whereby 'organisations may attempt to balance, pacify, or bargain with external constituents'); (2) avoidance (defined as 'the organisational attempt to preclude the necessity of conformity'); (3) defiance (which involves dismissing, challenging or attacking sources of institutional pressure); and (4) manipulation (a 'purposeful and opportunistic attempt to co-opt, influence, or control institutional pressures and evaluations') (pp. 153-157). Applied in the present setting, such insights point towards possible heterogeneity in corporate responses to ESG ratings, underpinned by the strategic agency of rated entities.

The wider literature identifies several reasons why actors might resist, rather than conform to, organisational rankings and ratings. Amongst others, resistance may be motivated by the negative consequences of unfavourable evaluations, both for rated organisations and the people working for them (Sauder and Espeland 2009). Additionally, efforts to substantively improve, or even maintain, a ranking position or scores may also be costly (Tamimi and Sebastianelli 2017). Precisely for this reason, organisations are liable to "game" rankings and ratings. According to Espeland and Sauder (2007, p. 29), '[G]aming is about managing appearances and involves efforts to improve ranking factors without improving the characteristics the factors are designed to measure.' The notion that organisations attempt to avoid institutional pressures is of special interest here because it aligns with the concept of "decoupling", previously invoked in the CSR literature (e.g. Egels-Zandén 2007; Testa et al. 2018). This occurs when organisations seek to detach their outward-facing, formal structures from their everyday internal practices (Meyer and Rowan 1977). Through more symbolic and ritualistic compliance with external requirements, decoupling allows firms to accrue various benefits (enhanced legitimacy, an improved reputation, superior access to resources, etc.) without making potentially costly substantive changes from business-as-usual. Within the present context, corporations might game ESG ratings through decoupling-type behaviour, thereby creating a misleading impression of their true performance (Gauthier and Wooldridge 2018). In such a scenario, even if a firm's constituent scores and ratings improve, external evaluations will not necessarily contribute to substantive improvements in corporate sustainability.

\section{Understanding Heterogeneity}

The previous section introduced the possibility that responses to ESG ratings might vary. An important question concerns the factors which could influence corporations' conformity or resistance to ratings. Returning to an earlier theme, and drawing from a body of work within the frame of stakeholder theory, one possible determinant is demand from stakeholders (Donaldson and Preston 1995). Managers will often have to prioritise some stakeholder claims over others (Mitchell et al. 1997). From the perspective of resource dependence theory (Pfeffer and Salancik 1978), influential stakeholders will be those with ownership or control over resources which are critical for organisational success. It follows that if firms perceive that powerful stakeholders value the attributes measured by ESG ratings, they are more likely to 'conform and perform' (Gioia and Corley 2002, p. 110) according to their criteria. Conversely, where firms face limited pressure from influential stakeholders over their ratings' performance, they may have more latitude to resist. Adopting a similar logic, corporate responses might vary across sectors. Firms in industries involving greater environmental or social impacts may experience higher stakeholder expectations and demands to actively and positively adjust to the requirements of ESG ratings (Hahn and Kühnen 2013).

Another set of factors which could influence responses are managerial values, attitudes and beliefs which, individually or in combination, shape an organisation's orientations towards external evaluations and the constituent attributes they measure. Taking a cue from Baumgartner (2013) and Dowling and Moran (2012), a firm's orientation toward ESG-type issues is likely to be underpinned by normative logics, which guide managers' understanding of an organisation's identity, purpose and ethical responsibilities. It is also likely to be shaped by economic and strategic logics, encapsulating organisational goals, and managerial beliefs about how best to achieve these strategically (Banerjee 2001; Malik 2015). Differences in managerial values and beliefs may result in what Ullmann (1985) describes as a passive or active 'strategic posture'. An active posture would suggest a firm conforming to ESG ratings, underpinned by positive managerial attitudes toward their value-enhancing possibilities or alignment with ethical principles. Conversely, managers may see little or no value in monitoring or responding to ESG ratings as part of their wider competitive or CSR strategy. In this situation, a passive strategic posture is more likely, possibly resulting in resistance-type behaviours (Ali et al. 2017).

Resources may also influence corporate responses. Organisations with more resources will be better placed to measure, collect and report on data used by rating agencies (Slager et al. 2012). They will also be able to invest more in changes to policy, practice and performance 
Table 1 Summary information on sustainability rating agencies (SRAs) operating in Italy

\begin{tabular}{|c|c|c|}
\hline SRA & Headquarters & Services $^{\mathrm{a}}$ \\
\hline MSCI & USA & ESG ratings, sustainability services, ESG/low carbon indices (e.g. MSCI Climate Change Indexes) \\
\hline Vigeo-Eiris & France & ESG ratings, CSR analysis, sustainability indices (e.g. Ethibel Sustainability Indices) \\
\hline ISS & Germany & $\begin{array}{l}\text { ESG ratings, sustainability and governance analysis and services, proxy voting, engagement services, ESG/low } \\
\text { carbon indices (e.g. Solactive ISS ESG Screened Index Series) }\end{array}$ \\
\hline ECPI & Italy & ESG ratings, sustainability services, ESG indices (e.g. ECPI Equity Index) \\
\hline Sustainalytics & Netherlands & $\begin{array}{l}\text { ESG (and associated) ratings, sustainability and governance analysis and services, engagement services, sustain- } \\
\text { ability indices (e.g. Global Sustainability Leaders Index) }\end{array}$ \\
\hline Refinitiv & UK and USA & ESG data, ESG/low carbon indices (e.g. Thomson Reuters/S-Network ESG Best Practice Indices) \\
\hline RobecoSAM & Switzerland & $\begin{array}{l}\text { ESG ratings, asset management, sustainability analysis and services, ESG/sustainability/low carbon indices (e.g. } \\
\text { Dow Jones Sustainability Index Series) }\end{array}$ \\
\hline FTSE Russell & UK & ESG ratings, data analysis and services, sustainability/low carbon indices (e.g. FTSE4Good Index Series) \\
\hline
\end{tabular}

Source Authors, based on company websites

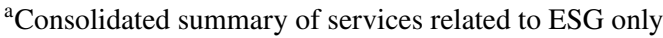

attributes measured by SRAs. Within the literature, the greater availability of "slack resources" has been used to explain why larger firms engage in more CSR practices (Campbell 2007), and disclose more ESG-related information (Tamimi and Sebastianelli 2017; Drempetic et al. 2019). As such, it is plausible to suggest that conformity to ESG ratings may be underpinned by superior corporate resources, and resistance a product of inadequate resources. Time is a further potentially relevant variable. As highlighted in Espeland and Sauder's (2007) work, initial dismissal of ratings can give way to greater strategic engagement, as rated entities acknowledge their importance and develop more sophisticated ways of responding. Likewise, Moos (2015) suggests that the cognitive legitimacy of ratings schemes may increase over time as they become more institutionalised, reducing the degree of discretion over how rated entities respond. Similar observations have been made in the wider literature on CSR which has recognised how stakeholder expectations of appropriate behaviour may change over time (e.g. Altura et al. forthcoming) and how firms may adjust CSR practice through learning and adaptation (e.g. Egels-Zandén 2014). What this suggests is that firms may move from an initial position of resistance to one of conformity. Finally, referencing previous quantitative work on ESG ratings, a firm's current ESG score might be expected to shape its response. The underlying idea is that poor ratings attract negative attention from external stakeholders, who exert pressure on corporations to improve their performance. Internally, too, firms may take measures to conform to ratings, aware of the potentially damaging consequences of a low score (Chatterji and Toffel 2010; Slager and Chapple 2016). Active responses aimed at positively adjusting to ratings and improving ESG evaluations might therefore be greater for corporations with relatively poor scores and/ or overall rank.

\section{Research Design and Methods}

Departing from the quantitative approach characterising most previous empirical work on ESG ratings, this paper adopts a qualitative research strategy. A particular advantage of this approach in the present context is that it is well suited to deriving - potentially new - categories from the data, and therefore identifying and characterising corporate responses (Mikko and Choi 2014). A qualitative, case study approach also provides in-depth, contextualised insights which can provide a richer account of human and organisational behaviour (Crouch and McKenzie 2006; Bryman 2016). As such, it can help unearth the context, processes and influences shaping corporate decision-making in the area of ESG ratings from the perspective of those being studied (i.e. individuals working for firms with a remit for ESG).

The empirical setting for our research is Italy. In focusing on a single country, we sought to remove cross-national sources of variability which might otherwise complicate the analysis. Italy is considered a relevant case because a non-trivial number of predominantly larger, publicly listed and/or multinational companies operating in the country have been subject to ESG ratings (Cucari et al. 2018). A summary of the main SRAs in Italy is provided in Table 1. Another reason for studying ESG ratings in this setting is that there is empirical evidence that firms in the country are increasingly responsive to CSR issues (Ormazabal and Sarriegi 2014). Amongst others, a growing number of large corporates are adopting sustainability reporting and assurance practices, and moreover across a wide range of ESG-related issues (Larrinaga et al. 2018; Romolini et al. 2014). At the same time, there is evidence of considerable inter-firm variability in CSR approaches and practices (e.g. Perrini et al. 2007; D'Amico et al. 2016), suggesting that Italy might be an appropriate setting in which to investigate whether firms respond differently to ESG ratings. 
Several distinctive features of Italian CSR are documented in the literature. One is an important role for the state in supporting various public CSR initiatives at the national and regional level. Another distinctive feature is a strong emphasis on addressing the needs of employees and local communities (Del Baldo et al. 2015; Perrini et al. 2007). The Italian business system is sometimes characterised as exhibiting an "implicit approach" to CSR wherein firms are primarily responsive to institutional (i.e. wider stakeholder) expectations. Yet, compared to Germany and the US, Habisch et al. (2011) find evidence that the level of involvement by investors in stakeholder dialogues is relatively high in Italy. The present paper provides an opportunity to examine whether these stylised features of the Italian system are manifest in the way firms react to ESG ratings.

In-depth, semi-structured interviews were undertaken with heads or managers of sustainability/CSR departments of companies operating in Italy. In order to identify the relevant population, websites of SRAs were consulted to locate companies which had been rated, or included in a relevant index. For the purposes of the study, we included well-known ESG rating agencies such as MSCI, Sustainalytics and Vigeo-Eiris, which also produce ESG, sustainability and/or low carbon indices. We also included the CDP (formerly known as the Carbon Disclosure Project) which, while a non-profit exclusively focused on environmentrelated aspects, is nevertheless an important actor engaged in performance evaluation. Information about companies' ESG ratings and their inclusion in indices was also collected through firms' websites and reports. Approximately 300 firms were found listed on various rating agencies' websites. From these, we selected companies rated by the largest number of SRAs and/or featured in one or more sustainability index. This resulted in a preliminary sample of 57 companies, which were subsequently contacted. Twenty-five replied and consented to be interviewed. Particular attention was paid to ensuring respondents were well placed to provide information about firms' responses to ESG ratings. In seven cases this person was not available. Interviews were thus carried out with 18 individuals representing a diversity of sectors (see Table 2). Six interviews were conducted in person, while the others were carried out over the telephone. Interviews were conducted during April-July 2018 and lasted between 35-70 min. All the interviews were undertaken in Italian and transcribed verbatim. Quotes presented in the paper were translated into English by one of the authors. Interviews were complemented by data from sustainability/integrated reports for companies in the sample which, amongst others, were used to better contextualise, interpret and verify statements made by respondents.

Thematic analysis was used to analyse the transcribed text. In the first stage, codes were developed which were felt to be relevant for our research questions (concerning the
Table 2 Sectoral composition of the sample

\begin{tabular}{ll}
\hline Company \# & Company sector \\
\hline 1 & Financial \\
2 & Utility (energy) \\
3 & High-tech industry \\
4 & Utility (energy) \\
5 & Mechanical engineering \\
6 & Financial \\
7 & Utility (energy) \\
8 & Manufacturing \\
9 & Multi-utility \\
10 & Utility (energy) \\
11 & Financial \\
12 & Multi-utility \\
13 & Utility (energy) \\
14 & Utility (energy) \\
15 & Utility (energy) \\
16 & Utility (energy) \\
17 & Services \\
18 & Services \\
\hline
\end{tabular}

how, why and substantive impact of firms' responses to ESG ratings). Subsequently, organising themes and sub-themes were created, wherein a theme "captures something important about the data... and represents some level of patterned response or meaning within the data set' (Braun and Clarke 2006, p. 82). This second stage involved collapsing relevant codes into coherent categories, examining their frequency and identifying common and divergent themes across the cases. It also involved a degree of abduction in that preexisting concepts were drawn on to inform the development, framing and subsequent interpretation of several thematic categories (Klag and Langley 2013). To take one example: the descriptors of 'active' and 'passive', previously invoked in the literature on organisational responses to institutional and stakeholder pressures, were enrolled because they offered a good 'situational fit' (Timmermans and Tavory 2012, p. 171) with the data.

Through the analysis, we developed a typology of responses to ESG ratings, together with an accompanying set of themes capturing mechanisms, influences and rationales. At the broadest level, we identified companies' responses as falling into two categories, resistance and conformity. We further found these types of response operated across two dimensions: (a) compliance with criteria established by SRAs, in terms of corresponding adjustments to organisational policies, processes and practices; and (b) interactions and engagement between companies and rating agencies. Our next step was to map out the responses of individual companies across these dimensions. To do so, each of the eighteen sample companies was assigned a score on a Likert 
Fig. 1 Typology of company responses to ESG ratings. Source Authors, based on interview responses

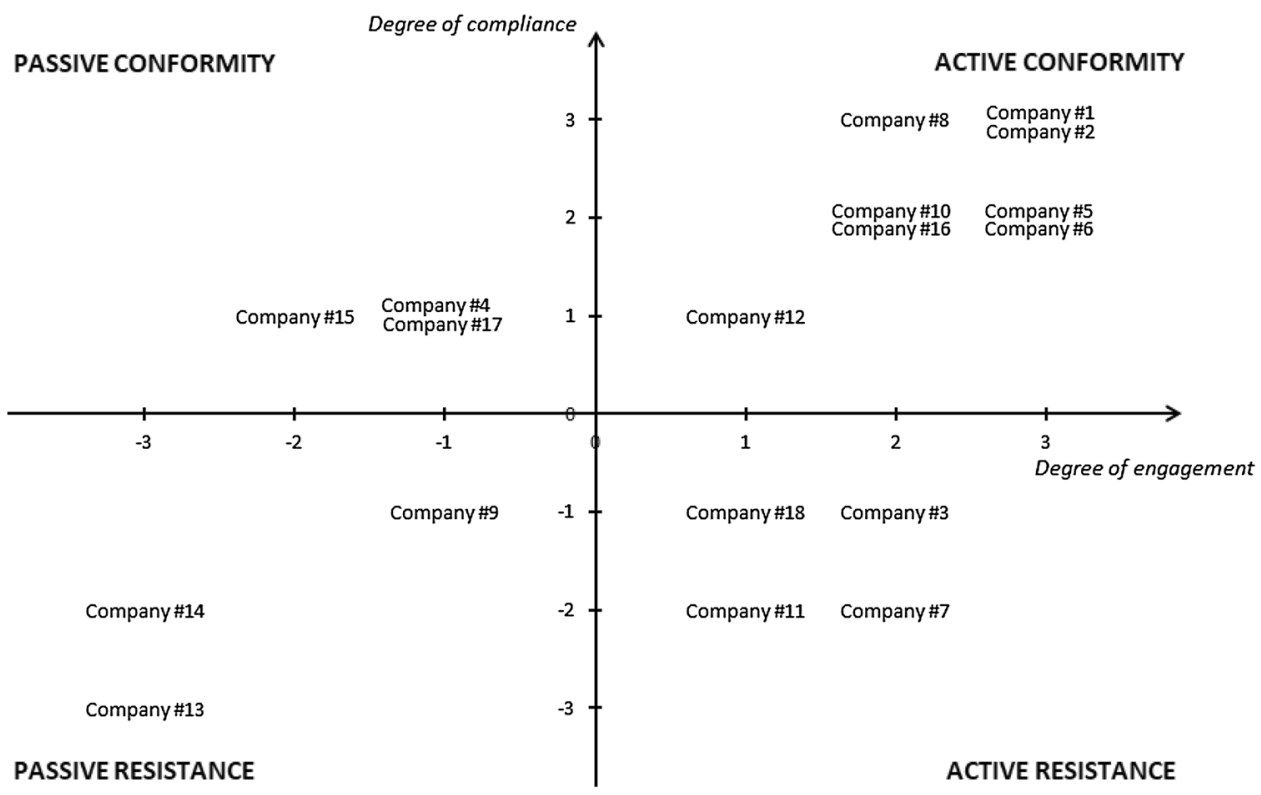

scale from -3 to +3 on their degree of resistance/conformity for (a) and (b) above, yielding a fourfold typology (see Appendix 1).

\section{Results and Analysis}

We begin by briefly describing our fourfold typology. This is followed by a more detailed analysis of firm responses within these categories, together with associated mechanisms and rationales.

\section{Responses to ESG Ratings}

Our findings provide evidence of considerable heterogeneity in how firms respond to ESG ratings (Fig. 1). Firms adjusting to ratings, albeit largely by changing aspects of their external disclosure and reporting practices to meet the informational needs of SRAs, lie in the passive conformity quadrant. Another set of companies which internalise ratings are located in the active conformity quadrant. Their common denominator is that they actively respond to ESG ratings, seeking to improve their scores through external reporting, but also through internal changes in CSR-related organisational processes and/or practices. The passive resistance quadrant contains companies resisting ratings by largely choosing to ignore them outright, while those in the active resistance quadrant seek to minimise the impact of ratings. Active conformity $(N=8)$ is the most common response, with just under half of the sample in this category. The other categorical responses each represent a broadly similar number of firms $(N=3-4)$.

\section{Passive Conformity}

Respondents categorised in this group affirmed that their company reacted, at least to some degree, to being evaluated and that ESG ratings were a real driver of change. Yet they largely responded in ways centred on communication and reporting. Most identified sustainability reports as the principal instrument to satisfy raters' information requests. The main mechanism triggered was improved disclosure to conform to the requirements of rating agencies. Three interviewees observed that the majority of SRAs looked mostly at documents published online. This inspired their companies to disclose more information-expanding sections and adding new ones on their websites and/or sustainability reports. As described by one interviewee:

We have seen this proliferation of assessments and we can't keep up with these requests... But at least we try to see what they [SRAs] are asking for from one year to the next and to adjust our sustainability report accordingly. If you look at our website, some things were not communicated before, we did not even think about communicating them.

The potential to attract investors was the primary motivating factor to better meet the information requirements of SRAs, including compiling questionnaires they received, and reviewing profile reports when "inaccuracies or incomplete information were evident". That many of their direct competitors were present in these ratings was also frequently cited as an incentive to complete surveys. One interviewee stated that: "If we were the only one in our sector to be rated, we would probably ignore them." Another reported that his company hired external consultants because it could 
not afford "two people working full time for a few months on these tasks." In this case, while reluctantly acknowledging the need to be responsive to information requirements, a lack of resources meant that the company was constrained in the degree to which it could optimise its scores:

We found ourselves fighting on the same field with companies which are giants compared to us. They [SRAs] compare us with [name of a competitor] because we are in the same sector. They use the same characteristics for analysis, but it is clear that we cannot have the same number of people for reporting, the same resources, etc.... so we try to answer them anyway, but we do not have time to investigate the why and the how of a certain score.

\section{Active Conformity}

Companies grouped in this category placed a strong emphasis on reputational value to explain the time and resources they dedicated to responding to raters' requests and to the analysis of results. The logic was that enhancing their scores would attract more investors. Six interviewees recognised the power of ratings in commensurating (Espeland and Stevens 1998) several aspects of CSR-related performance into a single score, providing a signal to the market and enabling investors to compare different companies. The term "flag" was used by three respondents to talk about ratings as being symbolic of their sustainability leadership. As stated by a head of CSR:

We use ratings to establish credibility with investors...

If you want to be a leader in CSR and attract investors, what does this mean? Above all, the external recognition that is given by the inclusion in the indices, which is a flag...

Companies underlined that over time they had learnt which ratings are considered more reliable by investors and which are more important for them in reputational terms. However, two companies made the point that investors are likely to purchase ESG data from diverse providers and make use of multiple ratings before considering an investment. For this reason, they considered it appropriate "to keep an eye on all the ratings," while paying particular attention to those regarded as the "most strategic". Such behaviour chimes with Pollock et al.'s (2018) concept of "tiering", whereby organisations sort and prioritise rankings/ratings according to their perceived significance. Two interviewees recognised that their companies started by adopting a more passive strategy at the beginning, becoming more active over time as they gained the knowledge "to build up an adequate response that actually complies with the agencies' requests."
All respondents in this category made explicit their interest in engaging with SRAs where possible. They commonly acknowledged the added value of direct contact with agencies:

A greater level of dialogue helps us to get more information regarding the methodologies they [SRAs] use. Since the involvement from our side is maximum, we appreciate when we can ask for further clarification after receiving the assessment/rating.

In the compilation phase of the questionnaires, the most common kind of engagement was participation in workshops, organised by some agencies to provide support with ESG reporting.

Companies in this category reported that ESG ratings had activated several mechanisms: enhanced reporting, internal organisational change, setting incentives, raised awareness, learning, benchmarking and policy implementation.

Enhanced Reporting All companies indicated that they dedicated more resources over the years to the production of an integrated report. Three noted that the complexity of reporting standards led them to include people with more technical expertise in their sustainability teams, such as engineers and physicists. They also recognised that the outcome of this process was a series of structured reports, which were "hardly understandable for the general public" and principally aimed at investors.

Internal Organisational Change Companies reported that their sustainability/CSR unit was composed of two or three people responsible for dealing with ratings and interacting with the agencies. However, they underlined that crafting responses to the questionnaires and analysing the results had become cross-disciplinary activities, and this allowed for collaboration between offices. All of them stated that they work closely with their colleagues from the investor relations team but also involve other departments (such as risk management or human resources) on ESG issues and create working groups across the company to further investigate poorly rated areas. One interviewee recognised the benefits of responding to SRA requests:

Look at the Dow Jones, which covers so many issues, providing specific and clear definitions of the subjects...It truly facilitates the activation of new processes of self-governance... We manage to engage other units and this spurs conversation around what can we do better.

As a result of increased internal engagement, interviewees stated that ESG ratings played a role in offering external legitimation of the function of the sustainability team itself. Indeed, they provided a lever for justifying sustainability 
requests across other offices and driving change. As one interviewee noted:

One thing is going to my colleagues saying: 'It would be great if we do something to reduce our emissions... and they say: yes, sure, I am going to make this my priority number 150.' But if instead, you go with requests coming from outside, which are backed by investors, well then...you are a bit more likely to create change.

Setting Incentives Four interviewees stated that their companies set an explicit goal of being included in sustainability indices. Specifically, they explained that their operational and senior managers, the executive team, and the Chief Executive Officer had personal performance objectives linked to the achievement of good scores in the DJSI, FTSE4Good, Vigeo-Eiris and CDP. However, one interviewee underlined that this attention to their ratings and the "direct impact they have on people's wallets" sometimes resulted in causing a distorting effect, insofar as "it obliged to introduce practices that aren't relevant to the company's core business, just to be compliant with them [SRA requests]."

Awareness ESG ratings were considered useful in detecting emerging issues related to ESG and to "keep track of the best practices and stay informed about the state-of-the-art." One interviewee defined ESG ratings as "translators of the international expectations concerning sustainability in businesses." Similarly, others framed ratings as "interpreters" and "proxies of stakeholder interests." As a consequence, participants recognised that ESG ratings made a decisive contribution to shifting the focus towards issues which were previously ignored. Another interviewee suggested that, as a result of this increased awareness, the company had activated new practices:

We first saw the booming interest in the topic of climate change, and subsequently the increasing importance of the theme of water. In both cases, the company's involvement in these topics was partial or, even in the case of water, non-existent. The ratings allowed us to understand the size of the problem, the reasons and the interest, and as such, we decided to initiate some management processes within the company.

Learning A mechanism commonly identified by companies was to look at the indicators that ratings underlined as needing improvement and striving to become better informed of best practices. Most of them stated that such analysis and learning were carried out internally, without using consultants. However, in some cases, they allocated specific resources to investigate certain areas that were poorly rated with RobecoSAM's Sustainability Services team. They also attended the workshops organised by the
CDP to "keep up with their methodologies." Potential forms of perverse learning (Meyer and Gupta 1994) were identified, with companies intent on finding out how to improve their outcome in performance measures, rather than their substantive sustainability performance. In fact, two interviewees said they were aware of commensuration ambiguities that could be strategically exploited. For instance, they admitted to hiring external consultants, not to better understand which sustainability strategies could be pursued, but only to acquire more insight on SRAs' scoring methodology. In the words of one participant:

Since everything depends on how they score your responses - for each question you can get one, two or half a point - we ask consultants to support us... They study the whole scoring methodology every year, so they know it inside out and suggest how to properly respond.

The tactic of gaining a better understanding of evaluation methodologies to improve scores has been documented in previous work on organisational ratings (Szper 2013).

Benchmarking Interviewees explained that they use ratings as a tool in the benchmarking of performance with other companies. Six companies indicated that they usually examine the areas where they score poorly compared to their peers and engage with the agencies to identify key areas for improvement. Four interviewees stated that they looked at what their competitors were doing in order to understand the critical aspects they had to implement in their strategy. One interviewee stated that in some cases the transparency of raters in disclosing information facilitated this benchmarking analysis. They gave the example of CDP questionnaires:

There was this question on emission reduction initiatives... We noticed that while we were able to complete only a single line of all the required information, other companies had provided ten lines of information...So I went to the persons responsible for the functions involved saying: 'It's fine that we treat information sensitively but look at what our competitors are disclosing...That's what we need to not to be outdone'.

Implementing New Policies To improve their scores, and as a result of enhanced awareness, learning and benchmarking analysis, companies claimed to have defined and activated new policies in several areas. When asked to provide examples, they cited those related to climate change, diversity and taxes. Three interviewees argued that their companies would not have introduced a human rights policy in their annual report if there had not been an explicit request by the agencies to do so. 
While companies in the active conformity category were responsive, several respondents nevertheless voiced frustration with ESG ratings. Two of them, for example, expressed annoyance about the difficulties and costs encountered in finding out more about their scores. As one remarked:

Last year, we did not understand which criteria they [a specific SRA] used: it just didn't add up. And when we asked for clarification, they redirected us to their commercial office... So in that case, you are forced to pay if you need some background information to use it as a tool to improve your score in the future.

\section{Passive Resistance}

When companies were not able to see any economic gains in terms of attracting investments or social benefits in terms of enhanced reputation, annoyance in receiving various SRA requests was expressed. They indicated no will to respond or initiate a dialogue with the agencies. They also claimed to disregard ESG ratings when taking strategic decisions within the company as they perceived no value added from the assessments or in some cases a clash between their priorities and the raters' criteria. Few, if any, adjustments to organisational policy, process and/or practice were made.

Ignoring The principal rationale here was that the costs of responding to SRAs and considering ESG ratings were not worth the effort. The assignment of poor scores was thus passively acknowledged and explained by the recognition of a divergence between the company's priorities and ratings' criteria. According to one interviewee, investments made to improve ESG scores run the risk of being entirely futile or "resulting in nothing more than façade operations detached from corporate culture." In this view, meeting raters' demands would interfere with business strategy. As stated by one interviewee:

Rating agencies keep on scoring us poorly because we do not encourage the diffusion of [redacted to protect company's anonymity]. But the point is that it would not be consistent with our industrial logic. Should I do it because raters asked me to? I don't think so, that's not useful for improving our positioning, so we just ignore them.

\section{Active Resistance}

Four companies reported that, since they did not see the changes being demanded by the agencies as consistent with their business goals, ESG ratings were rarely considered. However, they showed a certain level of engagement with the agencies to manifest their scepticism, or to influence their scoring methodologies.

Deflection These companies' resistant behaviour was motivated by a desire to channel resources towards direct engagement with investors while trying to minimise the impact of raters' requests. The main shortcoming of ESG ratings was attributed to the fact that "rating agencies rely too heavily on past performance and they are of limited use in predicting future performance, which is the objective of every investor." Two interviewees noted that many investors now have in-house ESG teams and their own ESG dashboards. Therefore, these companies prioritise the preparation of tailored information, focusing on particular topics in response to specific investor queries:

You have to establish a relationship of trust with your investors, and that requires time. But we have seen that one-on-one meetings are just much more profitable... Those who really want to invest in us need more detailed data on our company's ESG performance and, in any event, they will go beyond ESG ratings.

Lobbying In two cases, companies reported a sentiment of frustration at seeing how they were rated on issues deemed unrelated to their business, and in some cases considered irrelevant to their sustainability performance. This led them to adopt a strategy aimed at influencing the SRAs with regards to the methodologies used. One interviewee reported his wish to be assessed on the most material issues and said that the work of convincing the agencies had occasionally led to changes in the criteria on which they were evaluated:

We have spent years trying to persuade raters that biodiversity is a much more important issue to address than water consumption... of course we know it's important, but we just cannot do that much due to our structures. CDP and RobecoSAM eventually accepted our plea, giving less weight to that section, and taking our suggestions into account for their methodological reviews.

Another company stated that, in order to increase their chances of having an impact on the agencies, they sometimes looked for alliances with other companies-based in other European countries-which they knew were facing the same problems.

\section{Impact on ESG Performance}

When asked about the impact of ESG ratings on corporate sustainability performance, the majority of respondents denied any valuable contribution. Only those whose 
companies were actively conforming to rating agencies' criteria claimed to have defined and activated new policies in certain areas, e.g. human rights, diversity and governance issues. Three respondents explicitly recognised that the logic behind the formulation of these initiatives was mainly in order to achieve better scores, rather than a conscious strategy aimed at improving substantive performance. In the words of one sustainability manager:

We have never considered creating a policy on human rights. We only operate in Italy and we do not operate in the tomato supply chain - for us, that was not a sensitive issue. We decided to do it just to be compliant with rater requests. But that doesn't have any impact on our strategy. We have made a policy, but for us, it was just about gathering the information and presenting it in the right way.

In those cases where companies acknowledged that their ESG performance indicators had seen a significant improvement over the years, they attributed this progress to several factors. Amongst the most frequently cited were senior management's commitment to sustainability and the recognition that ESG best practices are the key to successful business strategies in the medium-to-long term. One interviewee explained that her company's ESG ratings "validate some of our practices primarily adopted for mitigating risk and strengthening the company's positive reputation." However, she could not see it the other way around, whereby the company had developed actions to enhance its ESG scores. Similarly, another interviewee described how, at most, SRA requests could be regarded as a "stimulus and pressure" to enhance awareness, but not as a direct cause of their performance improvements:

[Rating agency requests] might have indirectly spurred us to set some targets to reduce water consumption or focus on energy-saving solutions but I think this would have been the path anyway, no matter what...For us, these [environmentally sustainable practices] are crucial parts of our business, and our CEO believes in it thoroughly.

Two interviewees stressed that, although they play a role in raising internal awareness and promoting enhanced disclosure in the early phase of their companies' sustainability efforts, the impact of ESG ratings had diminished as they went forward. This is because SRAs were no longer able to take account of issues that were more financially material to the company. They stressed that decision-making processes were not significantly affected by the consideration of ESG ratings unless they were coupled with a special attention within the company or by more stringent regulatory pressures from outside.
When neither an endorsement from the executive level nor public pressure or other external incentives were registered, the potential of ESG ratings to lead to the adoption of better CSR practices was rarely acknowledged and interviewees were not able to offer compelling examples. They commonly noted that the definition of their corporate strategy - regarding any aspect, including ESG-is essentially an internal process. Two companies stressed that they had the "implicit obligation" to consider all the stakeholders in the formulation of the materiality matrix and strategy, and rating agencies were just one of these stakeholders. Another participant recognised that changes in the corporate culture require a much more compelling and pervasive stimulus than a rating "issued once a year and based on an analysis of publicly available sources."

The influence of ESG ratings was thus seen as more evident in driving corporate action on social and environmental reporting. All the companies interviewed, except those adopting a passive resistance approach, witnessed a consolidation of their internal data collection processes to respond to SRA questionnaires and evaluations. However, three interviewees stated that responding to ESG ratings mainly served the role of systematising what was already taking place within the company without affecting their internal strategies in any way. Furthermore, respondents suggested that ratings were only one of the factors influencing sustainability reporting, others including voluntary standards (such as the GRI and the UN Global Compact Principles) and regulatory requirements (such as the EU Directive on Disclosure of Non-financial and Diversity Information).

\section{Discussion}

Our findings make four important contributions to current understanding. First, echoing previous work on organisational rankings (Espeland and Sauder 2007; Scott and Orlikowski 2012; Szper 2013), we show that a significant number of companies (but not all) were reactive to ESG ratings. The very act of being rated did alter firm behaviour in ways which can be interpreted as conformity to criteria enshrined in the respective ratings. By far the most common response was disclosure, i.e. firms sought to make additional information available on attributes upon which they are evaluated or disclosed in a format which was better suited to the metrics used by SRAs. Fewer companies adjusted by changing their actual CSR policies, practices and/or performances. One possible explanation for this finding is the methodology used to compile ESG scores. Companies' ratings are, to a greater or lesser extent, influenced by the data available to SRAs such that firms can improve their scores on certain attributes simply by disclosing more or better quality information (Doyle 2018; Drempetic et al. 
2019). Enhancing disclosures is also far less costly, time consuming and disruptive than making substantive changes in ESG-related organisational practices.

The observation that firms had predominantly sought to conform to ratings through changes to disclosures is important because it points to the possibility of gaming (Espeland and Sauder 2007). Indeed, while some companies had accompanied improved disclosures with substantive changes in CSR-related policy and practice, for others this was decoupled from the reality of their sustainability performance. In common with similar forms of externally imposed organisational evaluations (e.g. Graf et al. 2019), we therefore show that ESG ratings may lead organisations to gaming-type behaviour.

A second contribution of our study is to identify a broader set of corporate responses to ESG ratings than previously documented in the literature. Conformity may well have been the dominant response amongst the firms in the sample. Yet, advancing on past work, we show that conformity took different forms and, moreover, was not the only response. Of note, certain firms resisted ESG ratings, a finding which provides a corrective to accounts which largely emphasise the homogenising effect of organisational evaluations (Chelli and Gendron 2013; Jabłecka 2012; Sauder and Espeland 2009). By exposing diversity, this paper confirms the predictions of Oliver (1991), who suggests that institutional pressures may give rise to heterogeneous organisational responses. Our typology of corporate responses overlaps with, but does not identically replicate, Oliver's. The passive conformity approach combines elements of acquiescence and compromise, with firms acceding to institutional demands but balancing these against other requirements. Passive resistance maps onto a strategy of defiance and, more specifically, the tactic of 'dismissing' whereby organisations ignore institutional requirements, while active resistance resembles Oliver's manipulation strategy which involves efforts to 'actively change or exert power over the content of the expectations themselves or the sources that seek to express or enforce them ' (ibid, p. 157). However, resonating with Pedersen's and Gwozdz's (2014) observations about the possibilities of strategic CSR, we also find evidence for responses which go beyond Oliver's typology. More specifically, the active conformity category captures several responses which are constitutive of an opportunityseeking approach, wherein firms seek to score well ("compete") on ESG metrics in order to gain competitive advantage. Corporate responses to ESG ratings are therefore not unlike other areas of CSR - with a sub-set of firms adopting a more proactive, value-seeking approach (Damert and Baumgartner 2018; Lee 2011).

A third important contribution is to provide novel insights into the under-researched question of why organisations respond differently to being evaluated (Rindova et al. 2018). One factor which stands out in explaining variability along the conformity/resistance axis was the degree to which companies believed that positively adjusting to ESG ratings provided business benefits. This involved two dimensions. One centred on external stakeholders: where better ESG scores or inclusion in indices was believed to help companies improve their reputation amongst investors, they were more likely to conform to the requirements and criteria of SRAs. Although this result is broadly consistent with stakeholder theory (Donaldson and Preston 1995), it is worth remembering that investors comprise primary stakeholders, rather than secondary ones. As such, our findings are aligned with a more conventional shareholder view of the firm (Flammer 2013), and confirm Habisch et al.'s (2011) finding about the relative significance of investors as stakeholders in Italy. Indeed, we found evidence that responses to specific ESG ratings partly depended on firms' perceptions regarding their standing, and whether investors would look at them. While companies recognised some SRAs as well-established players, they expressed uncertainty in how to deal with newcomers, whose relevant audience is unclear. Our findings therefore lend weight to Moos's (2015) observation that ratings must pass a "legitimacy threshold" in order to gain authority with rated parties, with firms more responsive to what were seen to be more legitimate SRAs.

A further dimension shaping firms' response to ESG ratings centred on the degree to which they were aligned with corporate strategy. Companies were more likely to exhibit a positive strategic posture (Ullmann 1985) toward ratings where managers believed that internalising ratings, enhancing relevant disclosures or making associated internal changes contributed to wider business strategy and objectives. Conversely, where managers felt that ESG ratings contributed little or nothing to corporate goals, companies were far more likely to ignore, dismiss or challenge them. The issue of materiality was mentioned several times throughout the interviews and resistance-type behaviours were mainly motivated by the perception that agencies' priorities were not well aligned with the peculiarities of an individual firm's business.

Closely associated with resistance was frustration. The multiplicity of requests drew strong criticism, with companies reporting having to deal with as many as thirty SRAs. This has led to a "reporting fatigue", together with a degree of resentment and cynicism towards raters and their motives. As one interviewee noted:

They [SRAs] are measuring similar things in different ways, with different platforms at the same time of the year; it has become a proper growing business, with ESG data providers that compete with each other and offer fee-based advisory services. 
Respondents also complained about how they felt judged on externally defined elements over which they had no control and/or of limited relevance to evaluating ESG-related risks, opportunities or performance. This raises an important point: resistance should not simply be interpreted as a strategy by firms to avoid ethical behaviour. It can moreover be driven by perceptions that ratings are too costly, time consuming and do not always contribute to enhancing firms' substantive contribution to sustainability.

A lack of internal resources was cited by a handful of respondents as inhibiting conformity to informational requests from SRAs. Such a finding is consistent with previous work on CSR-related disclosures (Chiu and Wang 2015). Yet the influence of ESG scores did not emerge as a significant factor. Respondents rarely mentioned their existing scores as a salient factor influencing their conformity or resistance. Two other factors previously invoked in the literature similarly did not appear to be important. We could discern no clear relationship between firms' sector and their response: companies belonging to the same sector (e.g. utilities) responded in different ways. The impact of time was also ambiguous: over time, active conformity grew amongst certain firms, while others became more resistant.

A further contribution is to provide insights into who governs through ESG ratings. As evidenced by their salience, investors emerged as an important set of actors, a finding which corroborates evidence about the growing incidence of ESG integration, investment and engagement (Cappucci 2018). Yet our paper additionally draws attention to the role of rated firms themselves who may use ESG ratings to self-govern their performance. In common with Searcy and Elkhawas (2012), we found evidence that ratings were used for benchmarking purposes, i.e. comparing own company scores against their peers. The growing application of benchmarking has been documented in the wider CSR literature (Provasnek et al. 2017). The findings here foreground the role of ESG ratings in these reflexive processes, and highlight the role of benchmarking as a mechanism of mimetic isomorphism (Parast and Adams 2012).

\section{Conclusions}

Our paper paints a more complex, differentiated picture of companies' responses to ESG ratings than portrayed in the existing literature. We show that there is no single response to ESG ratings, just as there is no single way in which firms respond more generally to CSR pressures (Dupire and M'Zali 2018). Instead, firms may react differently to being rated, captured by our fourfold typology of responses. The typology identifies conformity or resistance to ratings across two dimensions: (a) the degree to which companies adjust their policies, processes and practices to comply with ratings; and (b) the degree to which companies engage with ratings and SRAs. The empirical results suggest that the heterogeneity of responses was largely shaped by managers' perceptions of the instrumental "business value" of internalising and adjusting to ESG ratings.

The present paper is not without its limitations. Our sample is drawn from a single country with specific characteristics and is comparatively small. The empirical findings may be subject to selection bias since individuals with certain beliefs might have been more willing to participate in the research. Additionally, with just under half of the firms deriving from the utility sector, our sample is not representative of the overall population of rated companies. It is also possible that respondents may have provided biased answers to questions, for example, in the degree to which ESG ratings were a true driver of CSR (King et al. 2018). Indeed, even though interviewees provided what appeared to be candid answers, it was not often possible to corroborate their responses.

We nevertheless believe that our paper's findings have wider implications. One is for the study of corporate responses to organisational ratings and other performance measures (Rindova et al. 2018; Sroufe 2017). Our results bring into focus the value of exploring the potentially diverse sets of ways in which rated entities react to external sustainability- and ethics-related evaluations. The typology of responses developed above advances on previous work, both within the literature on ESG ratings, and broader scholarship on organisational ratings. While recognising discrete organisational strategies and tactics (Espeland and Sauder 2007; Locke 2014; Searcy and Elkhawas 2012), prior literature has only made limited progress in mapping these across different entities. An advantage of our approach is that it not only helps us to identify different generic types of response, but to locate common factors which might better explain possible heterogeneity.

Our findings also have implications for theory. Several theoretical mechanisms previously invoked in the literature-including reactivity and isomorphism-emphasise conformity to organisational ratings (e.g. Sharkey and Bromley 2014.). The results of the present paper do not entirely contradict these predictions. However, consistent with Pollock et al.'s (2018) work on rankings in the domain of enterprise solutions, they underscore the need to acknowledge the agency of actors in theorising organisational responses to external evaluations. More specifically, our paper points to an understanding of firms (and their managers) as calculative actors, whose approach is strongly shaped by selfassessments of the reputational, financial and strategic value of conforming to ESG ratings. This is not to deny the influence of a corporation's institutional environment arising, for example, from peers who may contribute to defining appropriate levels of ESG performance. Yet, it is nevertheless 
apparent that corporate responses are underpinned by a primary stakeholder-oriented, "materiality motivation" (Blowfield and Murray 2019), one which may result in resistance to ESG ratings where they are poorly aligned with business objectives.

This paper also speaks to wider debates about the substantive impact of ESG ratings (Gauthier and Wooldridge 2018; Oekom 2017; Shvarts et al. 2018). ESG ratings can, in certain cases, contribute to the incorporation of new CSR issues into firms' policy, practice and strategy; provoke internal organisational change required to more effectively operationalise business ethics and sustainability; and elevate the strategic importance of addressing ESG issues. Yet our findings sound a cautionary note about the degree to which such dynamics unequivocally translate into substantive improvements in sustainability performance. Even amongst those companies which adjusted to ratings, the main response was through actions centred on improved disclosures, with most respondents denying a significant impact on underlying $\mathrm{E}$, $\mathrm{S}$ or $\mathrm{G}$ aspects. Indeed, the requirements of SRAs are only one factor influencing corporations' CSR policies, practices and performances, and rarely the most important. In drawing these conclusions, our paper provides support to more critical accounts of informational governance, which challenge the idea that neoliberal practices of disclosure are sufficient to bring about significant changes in CSR-related behaviour (Christophers 2017; Leung and Snell 2019).

Our findings also have implications for business ethics. We found little evidence that entities had responded to ESG ratings by reflecting on, or rethinking, their values, ethical positions or principles. At one level, this is unsurprising: ESG ratings are not a "Polanyian" vehicle promulgated by civil society to (re-)embed societal values into the market (Klooster 2010). Rather, they are mostly commercial data products, increasingly marketed to investors on the grounds that they help in decision-making by providing material information on non-financial E, S and G factors. Yet herein lies two dangers of ratings. One is that, through their specific framing of ESG as a "business" issue, ratings run the risk of reducing ethical aspects to a commercial, calculative logic (Fleischman et al. 2019). This, in turn, may have the effect of "crowding out" ethics-based decision-making. Another closely related risk is that, by emphasising (and even rewarding) goal attainment in terms of scoring on measurable criteria, ESG ratings might distract attention away from ethical dimensions (Ims et al. 2014; Moore and Gino 2015). Work in other domains has documented how performance measurement may even lead to unethical behaviour as actors find ways of manipulating evaluations (e.g. Graf et al. 2019). To the extent that some firms in our sample appear to have gamed ratings, such observations receive a degree of endorsement.
Similarly, our paper raises ethical concerns about the interests served by the current ratings regime, characterised by multiple SRAs. For rated firms, responding to multiple information requests on an increasingly large set of $\mathrm{E}, \mathrm{S}$ and $\mathrm{G}$ aspects can be demanding, implying an opportunity cost of resources which might be more productively deployed elsewhere. This includes on other CSR-related activities. The multiplicity of requests from SRAs, together with their methodologies and scores, can also engender frustration, resentment and resistance which runs the risk of creating issue fatigue with corporate sustainability and ethics (Baden et al. 2009). This does not mean that ESG ratings are inherently antithetical to ethical business. A case in point: ratings are a potentially important tool which investors can use to shape the behaviour of firms in ways more closely aligned with their own ethical principles (Jackson et al. 2019). Ratings can also reveal ethical practice, as evidenced by certain corporations' principled stance not to cynically "play the ratings game", resisting them where they were felt not to positively contribute to addressing important firm-specific sustainability issues. Nevertheless, the ethical implications of what may seem a technical, innocuous and even virtuous enterprise of evaluating firms' ESG performance should be subject to critical inspection.

This paper is by no means the last word on ESG ratings. More work is needed to explore, document and unpack typologies of corporate responses across a wider range of geographic and organisational settings. There is additional scope for more anthropological work to explore the microdynamics of corporate responses (c.f. Arjaliès and Bansal 2018). Likewise, there is scope for complementary quantitative work, which examines the determinants of corporate responses across a larger sample of firms. Given the apparent frustration with the demands of rating agencies, it also seems apt to identify those information requests, interactions and feedbacks which productively inform superior CSR practice and performance, and those which largely engender resistance or gaming strategies. From an applied perspective, there is furthermore a need for work which examines how rating agencies could coordinate their data collection activities, as well as focus their efforts around sustainability aspects which are more financially material to corporations and investors. By addressing these aspects, it is the authors' hope that it might be possible to increase the "good" of ESG ratings, whilst reducing the "bad" (Rindova et al. 2018).

Open Access This article is licensed under a Creative Commons Attribution 4.0 International License, which permits use, sharing, adaptation, distribution and reproduction in any medium or format, as long as you give appropriate credit to the original author(s) and the source, provide a link to the Creative Commons licence, and indicate if changes were made. The images or other third party material in this article are included in the article's Creative Commons licence, unless indicated 
otherwise in a credit line to the material. If material is not included in the article's Creative Commons licence and your intended use is not permitted by statutory regulation or exceeds the permitted use, you will need to obtain permission directly from the copyright holder. To view a copy of this licence, visit http://creativecommons.org/licenses/by/4.0/.

\section{Appendix 1: Companies' Response Assessment Scale}

We categorised companies' responses to ESG ratings by evaluating two variables: (a) The degree of compliance: capturing adjustments to policies, processes and practices put in place by companies according to the criteria established by SRAs.

(b) The degree of engagement: capturing the level of interaction between companies and ESG SRAs.

To score each company on these respective variables, we developed sixfold classificatory schemes on $a-3$ to +3 scale (see Tables 3 and 4).

Table 3 Degree of compliance

\section{Classificatory descriptor}

-3 No changes to corporate policy, process or practice. The company believes that raters' priorities are not aligned with company priorities and shows an indifferent, even hostile, attitude to ratings

-2 No significant changes to corporate policy, process or practice. Company believes that the effort of meeting raters' requirements is not worth the cost, and does not bring added value

-1 Only minor changes to corporate policy, process or practice, with company seeking to avoid making any significant adjustments in response to ratings

1 The company takes ratings into account and changes aspects of CSR-related policy, process or practice, albeit only in communicative aspects related to reporting/disclosure. Implementation of some investments for the compilation of the questionnaires and sustainability reporting (e.g. in terms of recruitment and training of people working in the CSR/sustainability unit)

2 Same as 1 (above), but the firm also activates a limited number of changes to CSR-related policy, process or practice where consistent with corporate priorities and strategy

3 The company makes several changes in CSR-related policy, practice and strategy, and activates new organisational processes to meet SRA requests. Some evidence that the company makes use of ratings as an instrument of self-governance

Table 4 Degree of engagement

Classificatory descriptor

-3 Company ignores outright SRAs' requests, with complete absence of intention to initiate a dialogue with raters

-2 Responses delivered only to highly regarded questionnaires, but without any dialogue with SRAs

-1 Responses delivered to almost all questionnaire requests, but no dialogue with SRAs sought

1 Company responses delivered to all questionnaires and evidence of attempts to interact with some SRAs on an occasional basis

2 Responses delivered to all the questionnaires and a regular dialogue with specific agencies

3 Dialogue and regular engagement with many SRAs, also involving other corporate functions/divisions beyond the sustainability team 


\section{References}

Abramskiehn, D., Wang, D., \& Buchner, B. (2015). The Landscape of climate exposure for investors. San Francisco: Climate Policy Institute.

Adam, A. M., \& Shavit, T. (2008). How can a ratings-based method for assessing corporate social responsibility (CSR) provide an incentive to firms excluded from socially responsible investment indices to invest in cSR? Journal of Business Ethics, 82(4), 899-905.

Ali, W., Frynas, J. G., \& Mahmood, Z. (2017). Determinants of corporate social responsibility (CSR) disclosure in developed and developing countries: A literature review. Corporate Responsibility and Environmental Management, 24(4), 273-294.

Altura, T. G., Lawrence, A. T., \& Roman, R. M. (forthcoming). The global diffusion of supply chain codes of conduct: Market, nonmarket, and time-dependent effects. Business \& Society. https:// doi.org/10.1177/0007650319873654

Amel-Zadeh, A., \& Serafeim, G. (2018). Why and how investors use ESG information: Evidence from a global survey. Financial Analysts Journal, 74(3), 87-103.

Aouadi, A., \& Marsat, S. (2018). Do ESG controversies matter for firm value? Evidence from international data. Journal of Business Ethics, 151(4), 1027-1047.

Arjaliès, D.-L., \& Bansal, P. (2018). Beyond numbers: How investment managers accommodate societal issues in financial decisions. Organization Studies, 39(5-6), 691-719.

Avetisyan, E., \& Hockerts, K. (2017). The consolidation of the ESG rating industry as an enactment of institutional retrogression. Business Strategy and the Environment, 26(3), 316-330.

Baden, D. A., Harwood, I. A., \& Woodward, D. G. (2009). The effect of buyer pressure on suppliers in SMEs to demonstrate CSR practices: An added incentive or counter productive? European Management Journal, 27(6), 429-444.

Banerjee, S. B. (2001). Managerial perceptions of corporate environmentalism: interpretations from industry and strategic implications for organizations. Journal of Management Studies, 38(4), 489-513.

Baumgartner, R. J. (2013). Managing corporate sustainability and CSR: A conceptual framework combining values, strategies and instruments contributing to sustainable development. Corporate Social Responsibility and Environmental Management, 21(5), 258-271.

Blowfield, M., \& Murray, A. (2019). Corporate social responsibility (5th ed.). Oxford: Oxford University Press.

Boxenbaum, E., \& Jonsson, S. (2008). Isomorphism, diffusion and decoupling. In R. Greenwood, C. Oliver, K. Sahlin, \& R. Suddaby (Eds.), The SAGE Handbook of organizational institutionalism (pp. 78-98). London: Sage.

Braun, V., \& Clarke, V. (2006). Using thematic analysis in psychology. Qualitative Research in Psychology, 3(2), 77-101.

Bryman, A. (2016). Social research methods. Oxford: Oxford University Press.

Busch, T., Bauer, R., \& Orlitzky, M. (2016). Sustainable development and financial markets: Old paths and new avenues. Business \& Society, 55(3), 303-329.

Campbell, J. L. (2007). Why would corporations behave in socially responsible ways? An institutional theory of corporate social responsibility. The Academy of Management Review, 32(3), 946-967.

Cappucci, M. (2018). The ESG integration paradox. Journal of Applied Corporate Finance, 30(2), 22-28.

Chatterji, A. K., \& Toffel, M. W. (2010). How firms respond to being rated. Strategic Management Journal, 31(9), 917-945.

Chatterji, A. K., Durand, R., Levine, D. I., \& Touboul, S. (2016). Do ratings of firms converge? Implications for managers, investors and strategy researchers. Strategic Management Journal, 37(8), $1597-1614$.

Chelli, M., \& Gendron, Y. (2013). Sustainability ratings and the disciplinary power of the ideology of numbers. Journal of Business Ethics, 112(2), 187-203.

Chiu, T.-K., \& Wang, Y.-H. (2015). Determinants of social disclosure quality in Taiwan: An application of stakeholder theory. Journal of Business Ethics, 129(2), 379-398.

Christophers, B. (2017). Climate change and financial instability: Risk disclosure and the problematics of neoliberal governance. Annals of the American Association of Geographers, 107(5), 1108-1127.

Chrun, E., Dolšak, N., \& Praash, A. (2016). Corporate environmentalism: Motivations and mechanisms. Annual Review of Environment and Resources, 41(1), 341-362.

Clemens, B. W., \& Douglas, T. J. (2005). Understanding strategic responses to institutional pressures. Journal of Business Research, 58(9), 1205-1213.

Crane, A., Matten, D., Glozer, S., \& Spence, L. (2019). Business ethics: Managing corporate citizenship and sustainability in the age of globalization (5th ed.). Oxford: Oxford University Press.

Crouch, M., \& McKenzie, H. (2006). The logic of small samples in interview-based qualitative research. Social Science Information, 45(4), 483-499.

Cucari, N., De Falco, S. E., \& Orlando, B. (2018). Diversity of board of directors and environmental social governance: Evidence from Italian listed companies. Corporate Social Responsibility and Environmental Management, 25(3), 250-266.

Damert, M., \& Baumgartner, R. J. (2018). Intra-sectoral differences in climate change strategies: Evidence from the global automotive industry. Business Strategy and the Environment, 27(3), 265-281.

D'Amico, E., Coluccia, D., Fontana, S., \& Solimene, S. (2016). Factors influencing corporate environmental disclosure. Business Strategy and the Environment, 25(3), 178-192.

Déjean, F., Gond, J.-P., \& Leca, B. (2004). Measuring the unmeasured: An institutional entrepreneur strategy in an emerging industry. Human Relations, 57(6), 741-763.

Del Baldo, M. (2015). A state of the art of corporate social responsibility diffusion in Italy: Limits and potentials. In S. Idowu, R. Schmidpeter R. \& M. Fifka (Eds), Corporate Social Responsibility in Europe. CSR, Sustainability, Ethics \& Governance (pp.435-468). London: Springer.

Depoers, F., Jeanjean, T., \& Jérôme, T. (2016). Voluntary disclosure of greenhouse gas emissions: Contrasting the carbon disclosure project and corporate reports. Journal of Business Ethics, 134(3), 445-461.

DiMaggio, P., \& Powell, W. W. (1983). The iron cage revisited: Collective rationality and institutional isomorphism in organizational fields. American Sociological Review, 48(2), 147-160.

Donaldson, T., \& Preston, L. E. (1995). The stakeholder theory of the corporation: Concepts, evidence, and implications. Academy of Management Review, 20(1), 65-91.

Dowling, G., \& Moran, P. (2012). Corporate reputations: Built in or bolt on? California Management Review, 54(2), 25-42.

Doyle, T. M. (2018). Ratings that don't rate: the subjective world of ESG ratings agencies. Washington, D.C.: American Council for Capital Formation.

Drempetic, S., Klein, C., \& Zwergel, B. (2019). The influence of firm size on the ESG Score: Corporate sustainability ratings under review. Journal of Business Ethics. https://doi.org/10.1007/ s10551-019-04164-1.

Dupire, M., \& M'Zali, B. (2018). CSR strategies in response to competitive pressures. Journal of Business Ethics, 148(3), 603-623.

Duque-Grisales, E., \& Aguilera-Caracuel, J. (2019). Environmental, social and governance (ESG) scores and financial performance 
of multilatinas: Moderating effects of geographic international diversification and financial slack. Journal of Business Ethics. https://doi.org/10.1007/s10551-019-04177-w.

Eccles., R. G., \& Stroehle, J. C. (2018). Exploring social origins in the construction of ESG measures, Working Paper. Retrieved July 2 from https://ssrn.com/abstract=3212685 or https://dx.doi. org/10.2139/ssrn.3212685.

Egels-Zandén, N. (2007). Suppliers' compliance with MNCs' codes of conduct: Behind the scenes at Chinese toy suppliers. Journal of Business Ethics, 75(1), 45-62.

Egels-Zandén, N. (2014). Revisiting supplier compliance with MNC codes of conduct: Recoupling policy and practice at Chinese Toy suppliers. Journal of Business Ethics, 119(1), 59-75.

Elbasha, T., \& Avetisyan, E. (2018). A framework to study strategizing activities at the field level: The example of CSR rating agencies. European Management Journal, 36(1), 38-46.

Elsbach, K. D., \& Kramer, R. M. (1996). Members' responses to organizational identity threats: Encountering and countering the business week rankings. Administrative Science Quarterly, 41(3), 442-476.

Espeland, W. N., \& Sauder, M. (2007). Rankings and reactivity: How public measures recreate social worlds. American Journal of Sociology, 113(1), 1-40.

Espeland, W. N., \& Stevens, M. L. (1998). Commensuration as a social process. Annual Review of Sociology, 24(1), 313-343.

Flammer, C. (2013). Corporate social responsibility and shareholder reaction: the environmental awareness of investors. Academy of Management Journal, 56(3), 758-781.

Fleischman, G. M., Johnson, E. N., Walker, K. B., \& Valentine, S. R. (2019). Ethics versus outcomes: Managerial responses to incentive-driven and goal-induced employee behavior. Journal of Business Ethics, 158(4), 951-967.

Gauthier, J., \& Wooldridge, B. (2018). Sustainability ratings and organizational legitimacy: The role of compensating tactics. In G. Gal, O. Akisik, \& W. Wooldridge (Eds.), Sustainability and social responsibility: Regulation and reporting (pp. 141-157). Singapore: Springer.

Gioia, D. A., \& Corley, K. G. (2002). Being good versus looking good: business school rankings and the circean transformation from substance to image. Academy of Management Learning \& Education, 1(1), 107-120.

Graf, L., Wendler, W. S., Stumpf-Wollersheim, J., et al. (2019). Wanting more, getting less: Gaming performance measurement as a form of deviant workplace behavior. Journal of Business Ethics, 157(3), 753-773.

Habisch, A., Patelli, L., Pedrini, M., et al. (2011). Different talks with different folks: A comparative survey of stakeholder dialog in Germany, Italy, and the U.S. Journal of Business Ethics, 100(3), 381-404.

Hahn, R., \& Kühnen, M. (2013). Determinants of sustainability reporting: A review of results, trends, theory, and opportunities in an expanding field of research. Journal of Cleaner Production, 59(15), 5-21.

Hyatt, D. G., \& Berente, N. (2017). Substantive or symbolic environmental strategies? Effects of external and internal normative stakeholder pressures. Business Strategy and the Environment, 26(8), 1212-1234.

Ims, K. J., Pedersen, L. J. T., \& Zsolnai, L. J. (2014). How economic incentives may destroy social, ecological and existential values: The case of executive compensation. Journal of Business Ethics, 123(2), 353-360.

Jabłecka, J. (2012). Diversification, rankings and their conditions. general problems and the polish example. In W. Bienkowski, J. C. Brada, \& G. Stanley (Eds), The university in the age of globalization: rankings, resources and reforms (pp.26-61). London: Palgrave Macmillan.
Jackson, G., Bartosch, J., Avetisyan, E., et al. (2019). Mandatory nonfinancial disclosure and its influence on CSR: An international comparison. Journal of Business Ethics. https://doi.org/10.1007/ s10551-019-04200-0.

Kim, E.-H., \& Lyon, T. P. (2011). Strategic environmental disclosure: Evidence from the DOE's voluntary greenhouse gas registry. Journal of Environmental Economics and Management, 61, 311-326.

King, N., Horrocks, C., \& Brooks, J. (2018). Interviews in qualitative research. London: Sage.

Klag, M., \& Langley, A. (2013). Approaching the conceptual leap in qualitative research. International Journal of Management Reviews, 15(2), 149-166.

Klooster, D. (2010). Standardizing sustainable development? The Forest Stewardship Council's plantation policy review process as neoliberal environmental governance. Geoforum, 4l(1), 117-129.

Larrinaga, C., Rossi, A., Luque-Vilchez, M., \& Núñez-Nickel, M. (2018). Institutionalization of the contents of sustainability assurance services: A comparison between Italy and United States. Journal of Business Ethics. https://doi.org/10.1007/s1055 1-018-4014-z.

Lee, M.-D. P. (2011). Configuration of external influences: The combined effects of institutions and stakeholders on corporate social responsibility strategies. Journal of Business Ethics, 102(2), 281-298.

Leung, T. C. H., \& Snell, R. S. (2019). Strategies for social and environmental disclosure: The case of multinational gambling companies. Journal of Business Ethics. https://doi.org/10.1007/s1055 1-019-04190-z.

Locke, W. (2014). The intensification of rankings logic in an increasingly marketised higher education environment. European Journal of Education, 49(1), 77-90.

Malik, M. (2015). Value-enhancing capabilities of CSR: A brief review of contemporary literature. Journal of Business Ethics, 127(2), $419-438$.

Martins, L. L. (2005). A model of the effects of reputational rankings on organizational change. Organization Science, 16(6), 701-720.

Meyer, M. W., \& Gupta, V. (1994). The performance paradox. Research in Organizational Behaviour, 16, 309-369.

Meyer, J. W., \& Rowan, B. (1977). Institutionalized organizations: Formal structure as myth and ceremony. American Journal of Sociology, 83(2), 340-363.

Mikko, K., \& Choi, T. (2014). Renaissance of case research as a scientific method. Journal of Operations Management, 32(5), 232-240.

Mitchell, R. K., Agle, B. R., \& Wood, D. J. (1997). Toward a theory of stakeholder identification and salience: Defining the principle of who and what really counts. Academy of Management Review, 22(4), 853-886.

Moore, C., \& Gino, F. (2015). Approach, ability, aftermath: A psychological process framework of unethical behavior at work. The Academy of Management Annals, 9(1), 235-289.

Moos, C. (2015). A sociology of rankings: A longitudinal examination of the financial times MBA rankings. Doctor of Philosophy, London: London School of Economics and Political Science.

Oekom. (2017). The impact of socially responsible investments on companies: An empirical analysis. Munich: Oekom.

Oliver, C. (1991). Strategic responses to institutional processes. Academy of Management Review, 16(1), 145-179.

Ormazabal, M., \& Sarriegi, J. M. (2014). Environmental management evolution: Empirical evidence from Spain and Italy. Business Strategy and the Environment, 23(2), 73-88.

Parast, M. M., \& Adams, S. G. (2012). Corporate social responsibility, benchmarking, and organizational performance in the petroleum industry: A quality management perspective. 
International Journal of Production Economics, 139(2), 447-458.

Pedersen, E. R. G., \& Gwozdz, W. (2014). From resistance to opportunity-seeking: Strategic responses to institutional pressures for corporate social responsibility in the Nordic fashion industry. Journal of Business Ethics, 119(2), 245-264.

Perez-Batres, L. A., Doh, J. P., Miller, V. V., \& Pisani, M. J. (2012). Stakeholder pressures as determinants of CSR strategic choice: Why do firms choose symbolic versus substantive self-regulatory codes of conduct? Journal of Business Ethics, 110(2), 157-172.

Perrini, F., Russo, A., \& Tencati, A. J. (2007). CSR strategies of SMEs and large firms: Evidence from Italy. Journal of Business Ethics, 74(3), 285-300.

Pfeffer, J., \& Salancik, G. R. (1978). The external control of organizations: A resource dependence perspective. New York: Harper and Row.

Pollock, N., D’Adderio, L., Williams, R., \& Leforestier, L. (2018). Conforming or transforming? How organizations respond to multiple rankings. Accounting, Organizations and Society, 64, $55-68$.

Power, M. (1997). The audit society: Rituals of verification. Oxford: Oxford University Press.

Provasnek, A. K., Schmid, E., Geissler, B., \& Steiner, G. (2017). Sustainable corporate entrepreneurship: Performance and strategies toward innovation. Business Strategy and the Environment, 26(4), 521-535.

Rao, H. (2004). The social construction of reputation: Certification contests, legitimation, and the survival of organizations in the American automobile industry: 1895-1912. Strategic Management Journal, 15(S1), 29-44.

Rindova, V. P., Martins, L. L., Srinivas, S. B., \& Chandler, D. (2018). The good, the bad, and the ugly of organizational rankings: a multidisciplinary review of the literature and directions for future research. Journal of Management, 44(6), 2175-2208.

Romolini, A., Fissi, S., \& Gori, E. (2014). Scoring CSR reporting in listed companies: Evidence from Italian best practices. Corporate Social Responsibility and Environmental Management, 21(2), 65-81.

Sauder, M., \& Espeland, W. N. (2009). The discipline of rankings: Tight coupling and organizational change. American Sociological Review, 74(1), 63-82.

Scalet, S., \& Kelly, T. F. (2009). CSR rating agencies: What is their global impact? Journal of Business Ethics, 94(1), 69-88.

Scott, S. V., \& Orlikowski, W. J. (2012). Reconfiguring relations of accountability: Materialization of social media in the travel sector. Accounting, Organizations and Society, 37(1), 26-40.

Searcy, C., \& Buslovich, R. (2014). Corporate perspectives on the development and use of sustainability reports. Journal of Business Ethics, 121(2), 149-169.

Searcy, C., \& Elkhawas, D. (2012). Corporate sustainability ratings: an investigation into how corporations use the Dow Jones Sustainability Index. Journal of Cleaner Production, 35, 79-92.
Semenova, N., \& Hassel, L. G. (2015). On the validity of environmental performance metrics. Journal of Business Ethics, 132(2), 249-258.

Sharkey, A. J., \& Bromley, P. (2014). Can ratings have indirect effects? Evidence from the organizational response to peers' environmental ratings. American Sociological Review, 80(1), 63-91.

Shore, C., \& Wright, S. (2015). Audit culture revisited: Rankings, ratings, and the reassembling of society. Current Anthropology, 56(3), 421-444.

Shvarts, E., Pakhalov, A., Knizhnikov, A., \& Ametistova, L. (2018). Environmental rating of oil and gas companies in Russia: How assessment affects environmental transparency and performance. Business Strategy and the Environment, 27(7), 1023-1038.

Slager, R., \& Chapple, W. (2016). Carrot and tick? The role of financial market intermediaries in corporate social performance. Business \& Society, 55(3), 398-426.

Slager, R., Gond, J.-P., \& Moon, J. (2012). Standardization as institutional work: The regulatory power of a responsible investment standard. Organization Studies, 33(5-6), 763-790.

Sroufe, R. (2017). Integration and organizational change towards sustainability. Journal of Cleaner Production, 162, 315-329.

Suchman, M. C. (1995). Managing legitimacy: Strategic and institutional approaches. The Academy of Management Review, 20(3), 571-610.

SustainAbility. (2018). Rate the Raters 2018: Ratings Revisited. New York: SustainAbility.

Szper, R. (2013). Playing to the test: Organizational responses to third party ratings. VOLUNTAS: International Journal of Voluntary and Nonprofit Organizations, 24(4), 935-952.

Tamimi, N., \& Sebastianelli, R. (2017). Transparency among S\&P 500 companies: An analysis of ESG disclosure scores. Management Decision, 55(8), 1160-1680.

Testa, F., Boiral, O., \& Iraldo, F. (2018). Internalization of environmental practices and institutional complexity: Can stakeholders pressures encourage greenwashing? Journal of Business Ethics, 147(2), 287-307.

Timmermans, S., \& Tavory, I. (2012). Theory construction in qualitative research: From grounded theory to abductive analysis. Sociological Theory, 30(3), 167-186.

Ullmann, A. A. (1985). Data in search of a theory: A critical examination of the relationships among social performance, social disclosure, and economic performance of U.S. firms. Academy of Management Review, 10(3), 540-557.

van Duuren, E., Plantinga, A., \& Scholtens, B. (2016). ESG integration and the investment management process: Fundamental investing reinvented. Journal of Business Ethics, 138(3), 525-533.

Publisher's Note Springer Nature remains neutral with regard to jurisdictional claims in published maps and institutional affiliations. 